\title{
Management of central nervous system metastases
}

\author{
Sang-Hoon Lee, Kyung-Jae Park, Dong-Hyuk Park, Jang-Bo Lee, Shin-Hyuk Kang, Tai-Hyoung Cho, \\ Jung-Yul Park, Yong-Gu Jung, Junseok W Hur
}

Department of Neurosurgery, College of Medicine, Korea University, Seoul, Korea

Received: April 10, 2020

Accepted: April 17, 2020

\section{Corresponding Author:}

Junseok W Hur M.D., Ph.D.

Korea University Anam Hospital,

73, Goryeodae-ro, Seongbuk-gu,

Seoul, 02841, Korea

Tel: +82-2-920-5729

Fax: +82-2-929-0629

E-mail: hurjune@gmail.com
Central nervous system (CNS) metastases are divided into brain metastasis and intramedullary spinal cord metastasis (ISCM). Although the blood-brain barrier (BBB) and blood-spinal barrier (BSB) protect the brain and spinal cord, metastases occur when these barriers break under abnormal conditions. Brain metastasis accounts for the largest number of brain tumors, however, ISCM rarely occurs. For brain metastasis, whole brain radiotherapy (WBRT), stereotactic radiosurgery (SRS), surgery, and chemotherapy can be considered, and for ISCM, radiotherapy (RT), surgery, Cyberknife SRS, and chemotherapy can be considered. As treatment options vary depending on the patient's life expectancy, performance status (PF), extent and number of metastases, and the type of primary cancer, careful patient evaluation should be performed prior to treatment of CNS metastases.

Keywords: Brain; Central nervous system; metastases; Intramedullary spinal cord

\section{INTRODUCTION}

Among central nervous system (CNS) metastases, brain metastasis accounts majority cases compare to intramedullary spinal cord metastases (ISCM). Brain metastases remain the commonest type of brain tumor, being four times more common than primary brain tumors ${ }^{23}$. The management of patients with multiple brain metastases remains a difficult challenge for neurosurgeons. Treatment strategies for brain metastases depend on several factors. Some patients may be candidates for whole brain radiotherapy (WBRT), while others may require surgical resection followed by WBRT or local radiation therapy. Stereotactic radiosurgery (SRS) has added another dimension to the management of these lesions. The patient with metastatic brain tumor has a poor prognosis, and historically, treatment has generally consisted of administering WBRT after the diagnosis of multiple brain metastases is confirmed. However, nowadays, surgery has an important role in management for carefully selected cases. Surgery provides definite and accurate diagnosis, reduces intracranial mass effect, improves neurological symptoms, and may also improve overall survival (OS), all with low morbidity and mortality rates ${ }^{29)}$. It is generally accepted that to benefit from surgery, a patient with brain metastases must have reasonable medical fitness, with a systemic disease process amenable to benefit from local tumor control ${ }^{30)}$. Unlike brain metastasis, the role of surgical treatment in ISCM is controversial. Chemotherapy is usually considered by the type of primary cancer and applied for systemic control, however, the efficacy for the ISCM is unclear. The RT is generally considered as a palliative treatment for ISCM treatment ${ }^{16,20)}$. 


\section{EPIDEMIOLOGY}

The majority of brain metastases originate from one of three primary malignancies; lung cancer $(40 \%-50 \%)$, breast cancer (15\%-25\%), and melanoma (5\%-20\%). Among these, melanoma has the highest propensity to metastasize to the brain, with a $50 \%$ rate of brain involvement reported in patients dying of melanoma $^{2)}$. The frequency of metastatic brain tumors appears to be rising as a result of superior imaging modalities and earlier detection as well as longer survival after a primary cancer diagnosis because of more effective treatment of systemic disease ${ }^{11)}$. In the case of ISCM, lung cancer metastases (54\%) is the most common cause, followed by breast cancer metastases $(11 \%)^{19)}$. ISCM is a rare systemic cancer that autopsy studies have confirmed that ISCM is present in $0.9 \%$ to $2.1 \%$ of cancer patients. However, almost $95 \%$ of these lesions are clinically silent and remain undiagnosed before death, so they are actually less frequently encountered in practice ${ }^{7,9,10,18,31,36)}$.

\section{PATHOPHYSIOLOGY}

Under physiologic condition, CNS metastases hardly occur because of the firm blood-brain barrier (BBB) and blood-spinal barrier (BSB). However, in pathologic condition, inflammatory mediators cause increased permeability of the BBB/BSB. In this environment, cancer cells can attach to microvascular endothelial cells and invade the BBB/BSB, cause CNS metastases ${ }^{1,14)}$. A typical CNS metastases route is hematogeneous spreading. In brain metastasis, arterial spreading is known as a major cause, and venous spreading through Batson plexus is also considered as an important route for ISCM ${ }^{10,13,17,18,31,34)}$. Leptomeningeal dissemination by the cerebrospinal fluid (CSF) is also an important metastasis mechanism. In particular, it explains why the brain and ISCM often appear simultaneously ${ }^{9,31)}$. Direct invasion is also known as a case of metastasis, however, this is mainly limited in the case of $\mathrm{ISCM}^{9,37)}$.

\section{CLINICAL ASSESSMENTS}

The management of brain metastases can be divided into symptomatic and therapeutic strategies. Symptomatic therapy often includes corticosteroids to reduce peritumoral edema and anticonvulsants to prevent recurrent seizures. In addition, there is accumulating data to suggest that medications such as methylphenidate and donepezil can improve cognition, mood, and quality of life in patients with brain tumors ${ }^{26,35)}$. Therapeutic approaches to brain metastases include surgery, WBRT, SRS, and chemotherapy. Many patients are treated with a combination of these, and treatment decisions must take concern about factors such as patient age, functional status, primary tumor type, extent of extracranial disease, prior therapies, and number of intracranial lesions. Most ISCM patients are diagnosed with a neurological deficit. Ninety-three $\%$ of the patients showed motor dysfunction, $78 \%$ of the patients showed sensory abnormalities, and $62 \%$ of the patients showed urinogenital dysfunction ${ }^{16}$. For patients who previously diagnosed with primary cancer, ISCM can be considered, but if an intramedullary spinal cord tumor is diagnosed without knowing the primary cancer, it is highly likely to be mistaken for a primary tumor. While the surgery is the treatment of choice for primary intramedullary tumor, in contrast, surgery is performed in highly selective cases for ISCM. Careful diagnosis is needed prior to the treatment.

\section{TREATMENT MODALITIES - BRAIN METASTASIS}

\section{Systemic chemotherapy}

Chemotherapy has traditionally played a limited role in the treatment of brain metastases, and has been reserved for patients who have failed other treatment modalities or for diseases known to be "chemo-sensitive," such as lymphoma, small-cell lung cancer, germ-cell tumor and breast cancer ${ }^{11)}$. Incredulous stance regarding the usefulness of chemotherapy for brain metastases arises from the reason that most agents cannot cross the $\mathrm{BBB}$, because of their large molecular weight or hydrophilic property. The degree to which a given agent is believed to penetrate the BBB is usually based on pharmacokinetic animal and/or human studies comparing plasma with CSF drug concentrations after intravenous or oral administration. This method may underestimate the concentration of drug delivered to the tumor, however, because brain metastases are known to have local BBB breakdown (demonstrated on magnetic resonance imaging (MRI) by contrast enhancement and peritumoral edema). This is corroborated by studies showing roughly equivalent intracranial and extracranial response rates to chemotherapeutic agents assumed to have little BBB penetration, particularly when first-line agents for the systemic cancer are chosen ${ }^{4,6,33}$. The success of an agent may therefore rest more heavily upon its inherent activity against the systemic tumor than its putative ability to cross the BBB.

\section{Radiotherapy}

The mainstay of treatment for brain metastases over the past five decades has been corticosteroids and WBRT. Nonrandomized studies suggest that WBRT increases the median survival 
time by 3-4 months over approximately 1 month without treatment and 2 months with corticosteroids alone. Although reports of the response rate after WBRT alone vary, complete responses (CRs) or partial responses (PRs) have been documented in approximately $60 \%$ of patients in randomized controlled studies conducted by the radiation-therapy oncology group ${ }^{21)}$. Stasis or Improvement of neurologic symptoms occurs nearly the same proportion, even though symptom response defined separately in studies ${ }^{5)}$.

\section{SRS}

Although there is controversy exists, particularly those with a limited number of brain metastases, can be treated effectively with SRS alone ${ }^{11)}$. The assumed rationale for exclusion of WBRT is to spare patients the risk for late neurotoxicity from WBRT. Patients who were not treated upfront WBRT are typically monitored closely with serial MRI scans and treated with WBRT or additional SRS at recurrence ${ }^{11)}$.

\section{Surgery}

Management of patients with brain metastases has been evolving over time, with a general tendency towards a more aggressive treatment approach ${ }^{22)}$. Benefits of surgical resection include the provision of an accurate and definite diagnosis, immediate relief of neurological symptoms caused by extensive perilesional edema or mass effect, and local control of disease. Advances in surgical technique have led to lower rates of morbidity and mortality ${ }^{3)}$. Muacevic et al., demonstrate in their retrospective review of management of solitary metastasis of less than $3.5 \mathrm{~cm}$ of diameter concluded that result of surgery with WBRT is comparable to SRS in local tumor control rate ${ }^{27)}$.

\section{TREATMENT MODALITIES - ISCM}

\section{Radiotherapy}

The RT is considered as standard therapy for palliative treatment for ISCM ${ }^{8,10,13,18,38)}$. However, the efficacy is limited to radiosensitive tumor as small cell carcinoma, breast carcinoma, or lymphoma ${ }^{8,13,15,28,38)}$. Furthermore, radiation myelitis due to radiotoxicity should be considered.

\section{Surgery}

Surgery should be performed in highly selective patients. They should have good performance status, single CNS metastasis, and long enough life expectancy. In surgical technical aspect, as the microscopic surgical skill has been advanced and neurophysiologic intraoperative monitoring (IOM) has been developed, surgical outcome gradually improved. Some groups claim that the ISCM shows fair borderline that normal neural structure is well preserved along surgery, however, some groups assert the opposite $^{12,25)}$. There is little evidence that surgical resection could improve OS, however, neurologic improvement has been achieved in some reports ${ }^{12,40)}$.

\section{Chemotherapy}

As the BSB block the chemical, chemotherapy has little effect for ISCM treatment ${ }^{20)}$. However, if the primary cancer is suitable for specific chemotherapy, it could be applied as adjuvant therapy for RT or surgery ${ }^{19)}$.

\section{Steroid}

Steroid can reduce spinal cord edema and stabilize BSB, which helps relieving pain and delay neurologic deterioration. Even

Table 1. Management recommendation for brain metastases (adopted from Lin et al.) ${ }^{24)}$

\begin{tabular}{|c|c|c|c|c|}
\hline Consider systemic therapy & Consider WBRT & Consider SRS & Consider surgical resection & No treatment is reasonable \\
\hline $\begin{array}{l}\text { BM from highly chemotherapy- } \\
\text { sensitive primary tumor }\end{array}$ & $\begin{array}{l}\text { CNS and systemic progression } \\
\text { of disease, with few systemic } \\
\text { treatment options and poor } \\
\text { PS }\end{array}$ & $\begin{array}{l}\text { OM (1-3) or multiple BMs, } \\
\text { especially if PT is known to } \\
\text { be radiotherapy resistant }\end{array}$ & $\begin{array}{l}\text { Uncertain diagnosis of } \\
\text { CNS lesion(s) }\end{array}$ & $\begin{array}{l}\text { Systemic progression of disease, } \\
\text { with few treatment options } \\
\text { and poor PS }\end{array}$ \\
\hline $\begin{array}{l}\text { BM found on screening MRI } \\
\text { with planned systemic } \\
\text { treatment }\end{array}$ & $\begin{array}{l}\text { Multiple }(>3-10) \text { BMs, } \\
\text { especially if PT known to be } \\
\text { radiotherapy sensitive }\end{array}$ & $\begin{array}{l}\text { Postsurgical resection of a single } \\
\mathrm{BM} \text {, especially if } \geq 3 \mathrm{~cm} \text { and in } \\
\text { the posterior fossa }\end{array}$ & $\begin{array}{l}\text { 1-2 BMs, especially when } \\
\text { associated with extensive } \\
\text { cerebral edema }\end{array}$ & \\
\hline $\begin{array}{l}\text { BM from primary tumor } \\
\text { with identified molecular } \\
\text { alteration amenable to } \\
\text { targeted therapy }\end{array}$ & $\begin{array}{l}\text { Postsurgical resection of a } \\
\text { dominant BM with multiple } \\
\text { (>3-10) remaining BMs }\end{array}$ & $\begin{array}{l}\text { Local relapse after surgical } \\
\text { resection of a single BM }\end{array}$ & $\begin{array}{l}\text { Dominant BM in a critical } \\
\text { location }\end{array}$ & \\
\hline $\begin{array}{l}\text { Other therapeutic options have } \\
\text { been exhausted and there is a } \\
\text { reasonable drug available }\end{array}$ & $\begin{array}{l}\text { Salvage therapy for recurrent } \\
\text { BM after SRS or WBRT } \\
\text { failure }\end{array}$ & $\begin{array}{l}\text { Salvage therapy for recurrent } \\
\text { OM (1-3) after WBRT }\end{array}$ & & \\
\hline
\end{tabular}

BM: brain metastases; CNS: central nervous system; MRI: Magnetic-resonance imaging; OM: oligometastases; PS: performance status; SRS: stereotactic radiosurgery; WBRT: whole brain radiotherapy. 
though steroid cannot prolong survival, it is commonly used with other treatment modalities ${ }^{19,20)}$.

\section{Cyberknife Stereotactic Radiosurgery (SRS)}

Some groups reported ISCM were treated safely with Cyberknife SRS without severe complication ${ }^{32,39)}$. However, the total population is too small for the conclusion. Additional studies are essential to build stronger evidence.

\section{CONCLUSION}

Recommendation of clinical decision making in treatment of brain metastasis is below (Table 1$)^{24)}$. Many factors such as chemosensitivity of primary tumor, number and size of brain metastases (BM), clinical course such as local relapse or recurrence of $\mathrm{BM}$, and patient factors such as KPS should be considered. For ISCM, golden standard is still controversial. RT is generally performed and surgery is applied in selective patients. Cyberknife SRS could be considered as well. Due to the variety of treatment options, meticulous clinical assessment of patients and disease is mandatory.

\section{NOTES}

\section{Conflict of interest}

No potential conflict of interest relevant to this article was reported.

\section{REFERENCES}

1. Abbott NJ, Rönnbäck L, Hansson E. Astrocyte-endothelial interactions at the blood-brain barrier. Nat Rev Neurosci 2006; $7: 41$.

2. Amer MH, Al-Sarraf M, Baker LH, Vaitkevicius VK. Malignant melanoma and central nervous system metastases: incidence, diagnosis, treatment and survival. Cancer 1978;42:660-668.

3. Barker FG 2nd. Craniotomy for the resection of metastatic brain tumors in the U.S., 1988-2000: decreasing mortality and the effect of provider caseload. Cancer 2004;100:999-1007.

4. Bernardo G, Cuzzoni Q, Strada MR, Bernardo A, Brunetti G, Jedrychowska I, et al. First-line chemotherapy with vinorelbine, gemcitabine, and carboplatin in the treatment of brain metastases from non-small-cell lung cancer: a phase II study. Cancer Invest 2002;20:293-302.

5. Bezjak A, Adam J, Barton R, Panzarella T, Laperriere N, Wong CS, et al. Symptom response after palliative radiotherapy for patients with brain metastases. Eur J Cancer 2002;38:487-
496.

6. Boogerd W, Dalesio O, Bais EM, van der Sande JJ. Response of brain metastases from breast cancer to systemic chemotherapy. Cancer 1992;69:972-980.

7. Chason J, Walker FB, Landers JW. Metastatic carcinoma in the central nervous system and dorsal root ganglia. A prospective autopsy study. Cancer 1963;16:781-787.

8. Choucair A. Myelopathies in the cancer patient: incidence, presentation, diagnosis and management. Oncology 1991;5:25-31; discussion 35-27.

9. Costigan DA, Winkelman MD. Intramedullary spinal cord metastasis: a clinicopathological study of 13 cases. J Neurosurg $1985 ; 62: 227-233$

10. Edelson RN, Deck MD, Posner JB. Intramedullary spinal cord metastases: clinical and radiographic findings in nine cases. Neurology 1972;22:1222-1222.

11. Eichler AF, Loeffler JS. Multidisciplinary management of brain metastases. Oncologist 2007;12:884-898.

12. Goyal A, Yolcu Y, Kerezoudis P, Alvi MA, Krauss WE, Bydon M. Intramedullary spinal cord metastases: an institutional review of survival and outcomes. J Neurooncol 2019;142:347354.

13. Grem JL, Burgess J, Trump DL. Clinical features and natural history of intramedullary spinal cord metastasis. Cancer 1985; 56:2305-2314

14. Hawkins BT, Davis TP. The blood-brain barrier/neurovascular unit in health and disease. Pharmacol Rev 2005;57:173-185.

15. Holoye P, Libnoch J, Cox J, Kun L, Byhardt R, Almagro U, et al. Spinal cord metastasis in small cell carcinoma of the lung. Int $\mathrm{J}$ Radiat Oncol Biol Phys 1984;10:349-356.

16. Hrabalek L. Intramedullary spinal cord metastases: review of the literature. Biomed Pap Med Fac Univ Palacky Olomouc Czech Repub 2010;154:117-122.

17. Hur JW, Lee S, Lee JB, Cho TH, Park JY. What are MRI findings of Spine Benign Metastasizing Leiomyoma? Case report with literature review. Eur Spine J 2015;24 Suppl 4:S600-605.

18. Jellinger K, Kothbauer P, Sunder-Plassmann E, Weiss R. Intramedullary spinal cord metastases. J Neurol 1979;220:31-41.

19. Kalaycı M, Cağavi F, Gül S, Yenidünya S, Açıkgöz B. Intramedullary spinal cord metastases: diagnosis and treatment-an illustrated review. Acta neurochirurgica 2004;146:1347-1354.

20. Kalita O. Current insights into surgery for intramedullary spinal cord metastases: a literature review. Int J Surg Oncol 2011;2011.

21. Khuntia D, Brown P, Li J, Mehta MP. Whole-brain radiotherapy in the management of brain metastasis. J Clin Oncol 2006; 24:1295-1304. 
22. Lagerwaard FJ, Levendag PC. Prognostic factors in patients with brain metastases. Forum (Genova) 2001;11:27-46.

23. Laghari AA, Ahmed SI, Shamim MS. Role of surgery in brain metastases. J Pak Med Assoc 2017;67:1299-1300.

24. Lin X, DeAngelis LM. Treatment of Brain Metastases. J Clin Oncol 2015;33:3475-3484.

25. Lv J, Liu B, Quan X, Li C, Dong L, Liu M. Intramedullary spinal cord metastasis in malignancies: an institutional analysis and review. OncoTargets and therapy 2019;12:4741.

26. Meyers CA, Weitzner MA, Valentine AD, Levin VA. Methylphenidate therapy improves cognition, mood, and function of brain tumor patients. J Clin Oncol 1998;16:2522-2527.

27. Muacevic A, Kreth FW, Horstmann GA, Schmid-Elsaesser R, Wowra B, Steiger HJ, et al. Surgery and radiotherapy compared with gamma knife radiosurgery in the treatment of solitary cerebral metastases of small diameter. J Neurosurg 1999;91:3543.

28. Murphy K, Feld R, Evans W, Shepherd F, Perrin R, Sima A, et al. Intramedullary spinal cord metastases from small cell carcinoma of the lung. J Clin Oncol 1983;1:99-106.

29. Mut M. Surgical treatment of brain metastasis: a review. Clin Neurol Neurosurg 2012;114:1-8.

30. Narita Y, Shibui S. Strategy of surgery and radiation therapy for brain metastases. Int J Clin Oncol 2009; 14:275-280.

31. Okamoto H, Shinkai T, Matsuno Y, Saijo N. Intradural parenchymal involvement in the spinal subarachnoid space associated with primary lung cancer. Cancer 1993;72:2583-2588.

32. Parikh S, Heron DE. Fractionated radiosurgical management of intramedullary spinal cord metastasis: a case report and review of the literature. Clin Neurol Neurosurg 2009;111:858861.
33. Robinet G, Thomas P, Breton JL, Lena H, Gouva S, Dabouis G, et al. Results of a phase III study of early versus delayed whole brain radiotherapy with concurrent cisplatin and vinorelbine combination in inoperable brain metastasis of non- small-cell lung cancer: Groupe Francais de Pneumo-Cancerologie (GFPC) Protocol 95-1. Ann Oncol 2001;12:59-67.

34. Schiff D, O'Neill BP. Intramedullary spinal cord metastases: clinical features and treatment outcome. Neurology 1996; 47:906-912.

35. Shaw EG, Rosdhal R, D'Agostino RB Jr, Lovato J, Naughton MJ, Robbins ME, et al. Phase II study of donepezil in irradiated brain tumor patients: effect on cognitive function, mood, and quality of lif. J Clin Oncol 2006;24:1415-1420.

36. Smaltino F, Bernini F, Santoro S. Computerized tomography in the diagnosis of intramedullary metastases. Acta neurochirurgica 1980;52:299-303.

37. Sutter B, Arthur A, Laurent J, Chadduck J, Friehs G, Clarici G, et al. Treatment options and time course for intramedullary spinal cord metastasis Report of three cases and review of the literature. Neurosurg Focus 1998;4:E5.

38. Tognetti F, Lanzino G, Calbucci F. Metastases of the spinal cord from remote neoplasms: study of five cases. Surg Neurol 1988;30:220-227.

39. Veeravagu A, Lieberson RE, Mener A, Chen Y-R, Soltys SG, Gibbs IC, et al. CyberKnife stereotactic radiosurgery for the treatment of intramedullary spinal cord metastases. J Clin Neurosci 2012;19:1273-1277.

40. Wilson DA, Fusco DJ, Uschold TD, Spetzler RF, Chang SW. Survival and functional outcome after surgical resection of intramedullary spinal cord metastases. World Neurosurg 2012; 77:370-374. 